\title{
Vital Role of Ultrasound in the Era of COVID-19: Arriving at the Right Diagnosis Real Time
}

Amarja A Havaldar

\begin{abstract}
Ultrasound has become an integral part for assessment of critically ill patients. It has helped in diagnosing and treating critically ill patients. The added advantage of ultrasonography is that it is a fantastic diagnostic tool that is easily available at the bedside, repeatable, more objective, and has a steep learning curve. It has become fifth vital assessment along with inspection, palpation, percussion, and auscultation. In the current scenario of COVID-19 pandemic, the disease caused by virus ranges from mild influenza-like illness to severe acute respiratory illness (SARI). Among the patients developing SARI, few require hospitalization and might need intensive care management. As a critical care specialist, we need to keep our antenna up to look for other causes for SARI due to non-COVID etiology as well. This article describes algorithmic approach and vital role of ultrasonography while managing patients with respiratory distress.

Keywords: COVID-19, Training, Ultrasonography.

Indian Journal of Critical Care Medicine (2020): 10.5005/jp-journals-10071-23490
\end{abstract}

\section{INTRODUCTION}

Ultrasonography, once questioned about its utility while assessing lung pathology, with further developments in this field, has made a great impact in critical care management. ${ }^{1-3}$ In routine clinical assessment, it can be used for evaluating pathologies of lung, heart, abdomen, and venous system, which may contribute to the various causes for respiratory distress. ${ }^{1-5}$

COVID-19 pneumonia has characteristic ultrasonographic patterns, such as thickened pleura, subpleural consolidation. ${ }^{6}$ Peculiarly, as described in the literature, pleural effusion is not the typical finding of COVID pneumonia. There is a possibility that the patient can have COVID with other pathologies or non-COVID illness presenting with respiratory distress. ${ }^{6}$

Stepwise approach can help the clinician to get the correct diagnosis. Thanks to Lichtenstein and colleagues who have designed different protocols in the management of critically ill patients. ${ }^{7-10}$ One can follow bedside lung ultrasound evaluation and BLUE protocol integrated with Echocardiographic assessment. ${ }^{8}$

\section{Stepwise Approach Advised}

- Lung Ultrasound

- Look for pleural slide, lung point

- Assessment of each lung zone-evaluate for A lines, B lines, $A^{\prime}$ and $B^{\prime}$ profile,

- Look for the pleural effusion

- If there are no significant lung findings or patient has ' $A$ ' profile with good pleural sliding, still patient is having respiratory distress, look for DVT.

- If no DVT, then probably patient has bronchospasm or dynamic hyperinflation or AutoPEEP (positive end expiratory pressure).

- Use of echocardiography along with USG lung

- Look for chamber size

- Regional wall motion abnormality (RWMA)
Department of Critical Care Medicine, St Johns Hospital, Bengaluru, Karnataka, India

Corresponding Author: Amarja A Havaldar, Department of Critical Care Medicine, St Johns Hospital, Bengaluru, Karnataka, India, Phone: +91 9036082112, e-mail: amarjahavaldar@rediffmail.com

How to cite this article: Havaldar AA. Vital Role of Ultrasound in the Era of COVID-19: Arriving at the Right Diagnosis Real Time. Indian J Crit Care Med 2020;24(7):563-564.

Source of support: Nil

Conflict of interest: None

- LV filling pressure, E/e'

- Valves for any abnormality, clots

- RV strain and pericardial effusion or tamponade.

So majority of pathologies can be diagnosed with ultrasound.

This algorithm (Flowchart 1) shows stepwise approach to help in diagnosis. It starts with evaluation of pleural sliding.

\section{Any Role of CXR}

There is a possibility of error due to interobserver bias in interpretation. Chest $\mathrm{X}$-ray may give some clue but it is not a specific tool. ${ }^{11}$ So it's time to make ultrasonography as an integral part of training not only for emergency and critical care specialists but also for super-specialities. ${ }^{12}$

\section{Can We Use CT Scan?}

Computed tomography (CT) scan might help in diagnosing underlying lung disease and various other etiologies. While using CT scan in COVID era, one should think about risk of transporting these sick patients, risk of exposure for healthcare worker, additional use of PPE's by CT room personnel, and strict adherence to surface cleaning and disinfection protocols. ${ }^{6}$

(-) The Author(s). 2020 Open Access This article is distributed under the terms of the Creative Commons Attribution 4.0 International License (https://creativecommons. org/licenses/by-nc/4.0/), which permits unrestricted use, distribution, and non-commercial reproduction in any medium, provided you give appropriate credit to the original author(s) and the source, provide a link to the Creative Commons license, and indicate if changes were made. The Creative Commons Public Domain Dedication waiver (http://creativecommons.org/publicdomain/zero/1.0/) applies to the data made available in this article, unless otherwise stated. 
Flowchart 1: Simple algorithm for managing any patient with respiratory distress

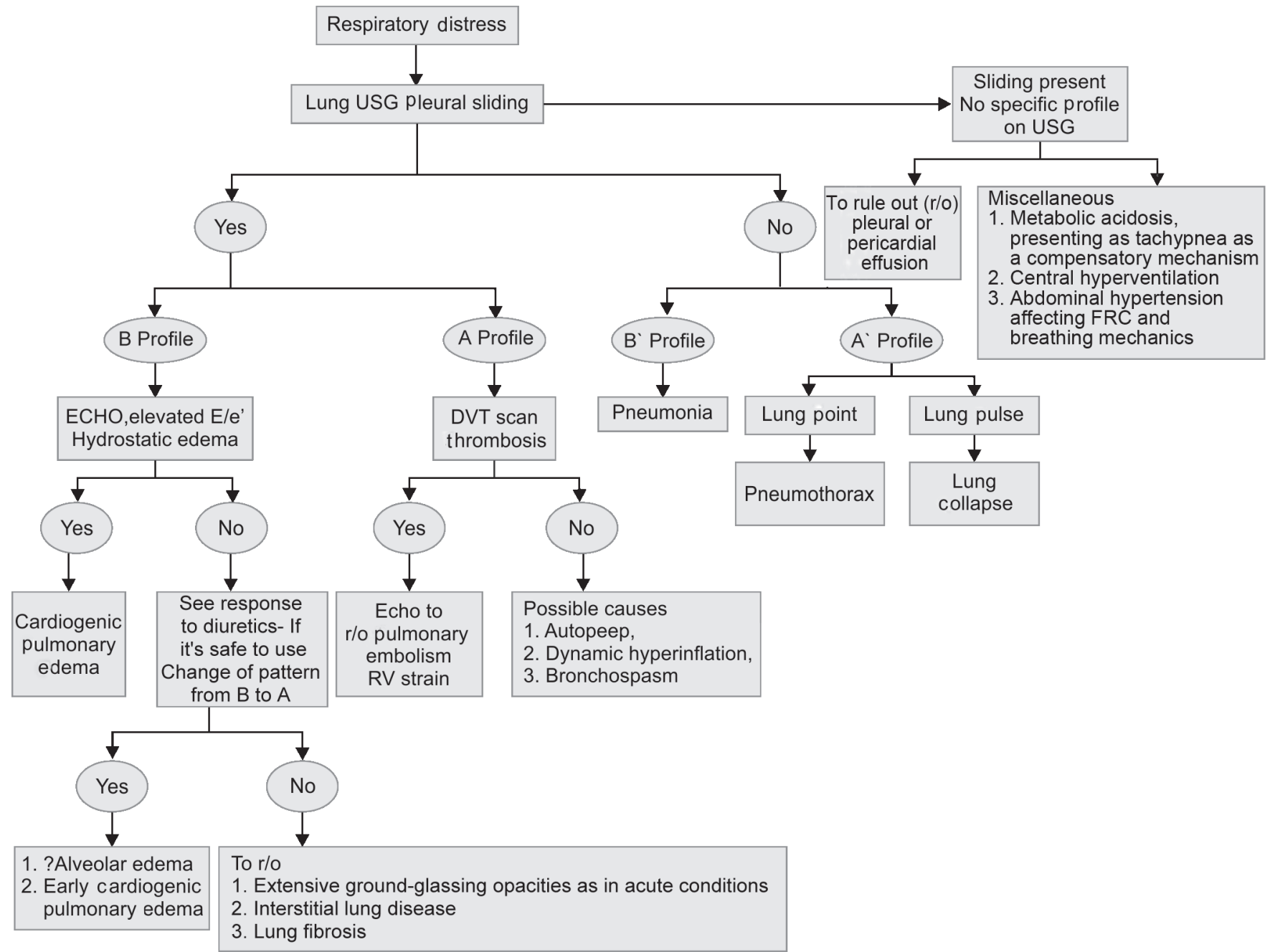

\section{Conclusion}

While managing patients during pandemic we need to keep high probability of patients having COVID illness causing pneumonia, but it may not be always the case. Presence of respiratory or cardiac comorbidities will alter the clinical findings. Need to remember, eyes do not see what the mind doesn't know.

\section{References}

1. Copetti R. Is lung ultrasound the stethoscope of the new millennium? definitely yes. Acta Medica Academica 2016;45(1):80. DOI: 10.5644/ ama2006-124.162.

2. Buonsenso D, Pata D, Chiaretti A. COVID-19 outbreak: less stethoscope, more ultrasound. Lancet Respirat Med 2020(5). DOI: 10.1016/S2213-2600(20)30120-X.

3. Volpicelli G, Lamorte A, Villén T. What's new in lung ultrasound during the COVID-19 pandemic. Intensive Care Med 2020(7):1-4. DOI: 10.1007/s00134-020-06048-9.

4. Lichtenstein D, Malbrain M. Lung ultrasound in the critically ill (LUCI): a translational discipline. Anaesthesiol Intens Ther 2017;49(5) 430-436. DOI: 10.5603/AIT.a2017.0063.

5. Reissig A, Copetti R, Kroegel C. Current role of emergency ultrasound of the chest. Crit Care Med 2011;39(4):839-845. DOI: 10.1097/ CCM.0b013e318206d6b8.
6. Peng QY, Wang XT, Zhang LN. Chinese Critical Care Ultrasound Study Group. Findings of lung ultrasonography of novel corona virus pneumonia during the 2019-2020 epidemic. Intens Care Med 2020(5):1. DOI: 10.1007/s00134-020-05996-6.

7. Lichtenstein D. Novel approaches to ultrasonography of the lung and pleural space: where are we now? Breathe 2017;13(2):100-111. DOI: $10.1183 / 20734735.004717$.

8. Lichtenstein DA, Meziere GA. Relevance of lung ultrasound in the diagnosis of acute respiratory failure*: the BLUE protocol. Chest 2008;134(1):117-125. DOI: 10.1378/chest.07-2800.

9. Lichtenstein $D$, Mezière $G$. A lung ultrasound sign allowing bedside distinction between pulmonary edema and COPD: the comet-tail artifact. Intens Care Med 1998;24(12):1331-1334. DOI: 10.1007/ s001340050771.

10. Lichtenstein DA. Lung ultrasound in the critically ill. Ann Intensive Care 2014;4(1):1. DOI: 10.1186/2110-5820-4-1.

11. Wunderink RG, Woldenberg LS, Zeiss J, Day CM, Ciemins J, Lacher DA. The radiologic diagnosis of autopsyproven ventilatorassociated pneumonia. Chest 1992;101(2):458-463. DOI: 10.1378/ chest.101.2.458.

12. Mayo PH, Beaulieu Y, Doelken P, Feller-Kopman D, Harrod C, Kaplan A, et al. American college of chest physicians/la société de réanimation de langue Française statement on competence in critical care ultrasonography. Chest 2009;135(4):1050-1060. DOI: 10.1378/ chest.08-2305. 